\title{
Total carbon dioxide and its bearing on the dissolved oxygen in the Oyashio and in the frontal region of the Kuroshio*
}

\author{
Yoshio Sugiura $^{1}$ and Hirozo Yoshimura ${ }^{2}$ \\ Meteorological Research Institute, Koenji-kita, Suginami, Tokyo ${ }^{1}$ and \\ Japan Meteorological Agency, Öte-Machi, Chiyoda, Tokyo ${ }^{2}$
}

(Received October 7, 1966; in revised form February 1, 1967)

\begin{abstract}
The amount of total carbon dioxide estimated from $\mathrm{pH}$ and alkalinity was plotted against AOU. Results obtained were compared with those of a phosphate $v$ s. AOU plot previously reported by the present authors. As a result, the following points were confirmed: 1) The relationship between total carbon dioxide and AOU is given by a straight line with a slope of about 100/270 in an atomic ratio of carbon to oxygen for a group of waters with equal chlorinity and temperature. 2) The atomic ratio of carbon to phosphorus of about 100 to 1 obtained from the comparison of the ratios of $\Sigma \mathrm{CO}_{2}$ to AOU and $\mathrm{P}$ to AOU coincides with the $\mathrm{C}$ to $\mathrm{P}$ ratio given by FLEMING for a composite plankton sample. 3) Total carbon dioxide consists of three components; oxidative total carbon dioxide, reserved total carbon dioxide proportional to chlorosity (major portion of reserved total carbon dioxide) and reserved total carbon dioxide independent of chlorosity (minor portion of reserved total carbon dioxide). 4) Chlorosity-independent portion of reserved total carbon dioxide, as well as reserved phosphate, is remarkably more abundant in the Oyashio waters than in the Kuroshio waters.
\end{abstract}

\section{INTRODUCTION}

In a previous study (SugrurA, 1966) it was shown that in waters with equal chlorinity and temperature, a plot of total carbon dioxide amount vs. AOU (the difference between the saturated and the observed amounts of dissolved oxygen) revealed a straight line with a slope of approximately 100 to 270 in the atomic ratio of carbon to oxygen. In the previous study, total carbon dioxide was determined by using a micro-diffusion method. In the present study, total carbon dioxide amount was calculated from $\mathrm{pH}$ values and alkalinity in waters of the Oyashio and the frontal region of the Kuroshio. And again, a straight line with the same slope was obtained from the total carbon dioxide amount $v$ s. AOU plot for waters with equal chlorinity and temperature.

Sugiura and Yoshimura (1964) discussed the relationship of phosphate to AOU in waters of the same regions. In the present paper, the relationship of total carbon dioxide to AOU was compared with that of phosphate to AOU.

* Presented at the 11th Pacific Science Congress, Tokyo, 1966. 


\section{Discussion}

The total carbon dioxide vs. AOU diagram

Fig. 1 shows the relationship between total carbon dioxide and AOU in waters of the Oyashio and the frontal region of the Kuroshio. In the figure, waters are classified into several groups of waters with equal density and chlorinity, in other words, equal chlorinity and temperature. In the diagram, points indicating waters with equal density and chlorinity fall on a straight line with a slope $(\Delta \mathrm{C} / \Delta \mathrm{O})$ of about 100 to 270 in the atomic ratio of carbon to oxygen. It is interesting to compare this trend with that of the phosphate to AOU diagram (Fig. 2), in which a straight line with a slope of about 1 to 270 in the atomic ratio of phosphorus to oxygen was obtained. From Figs. 1 and 2, an atomic ratio of carbon to phos. phorus of about 100 to 1 can be derived. The value coincides with that of the carbon to phosphorus ratio for a composite plankton sample (FlEming, 1940).

Fig. 1 indicates that the concentration of total carbon dioxide is given by the summation of AOU-dependent portion and AOU-independent portion. The former is called oxidative and the latter reserved. The amount of reserved total carbon dioxide is estimated as the amount of total carbon dioxide at zero AOU.

Fig. 3 shows the domains for different water types. Comparing Fig. 2 with Fig. 3, features common to both $\mathrm{P}: \mathrm{AOU}$ and $\Sigma \mathrm{CO}_{2}: \mathrm{AOU}$ diagrams are pointed out as follows: Concentrations of reserved total carbon dioxide and reserved phosphate are the lowest in waters with $\sigma_{t}$ 24.0-25.0 and chlorinity 19.1-19.3\%o (the Kuroshio

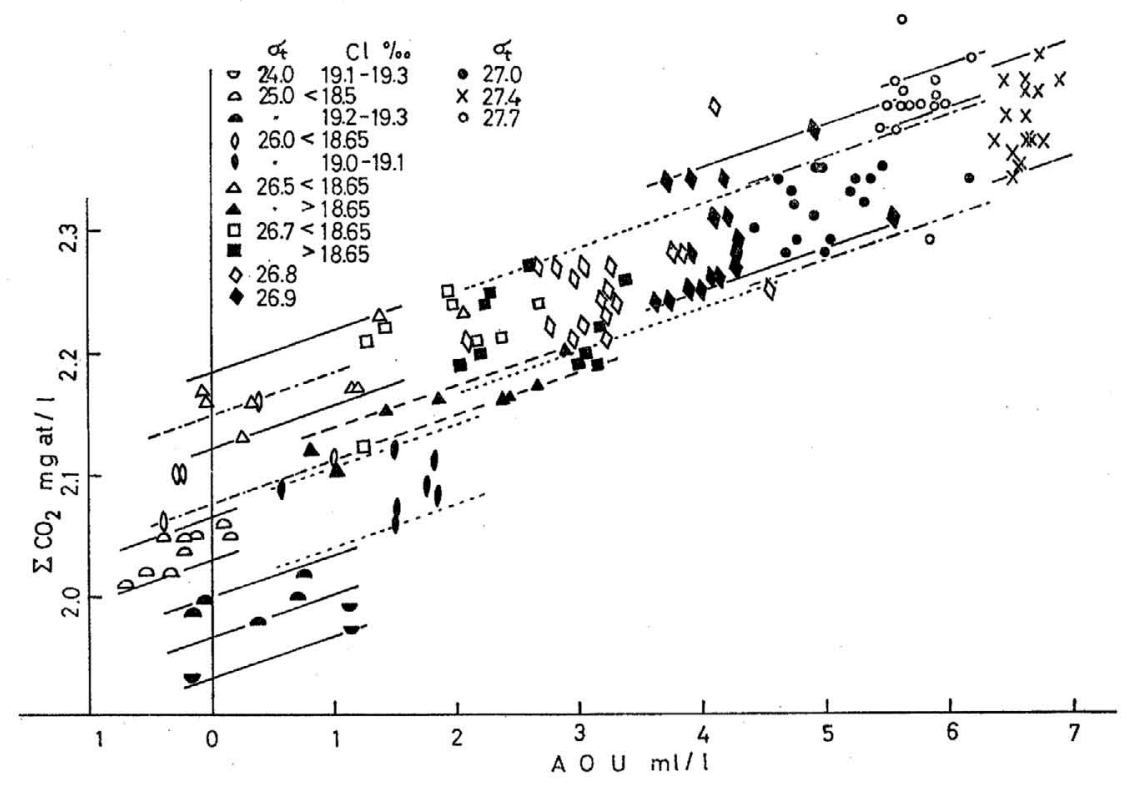

Fig. 1. The relationship of total carbon dioxide to AOU for waters of the Oyashio and the frontal region of the Kuroshio. 


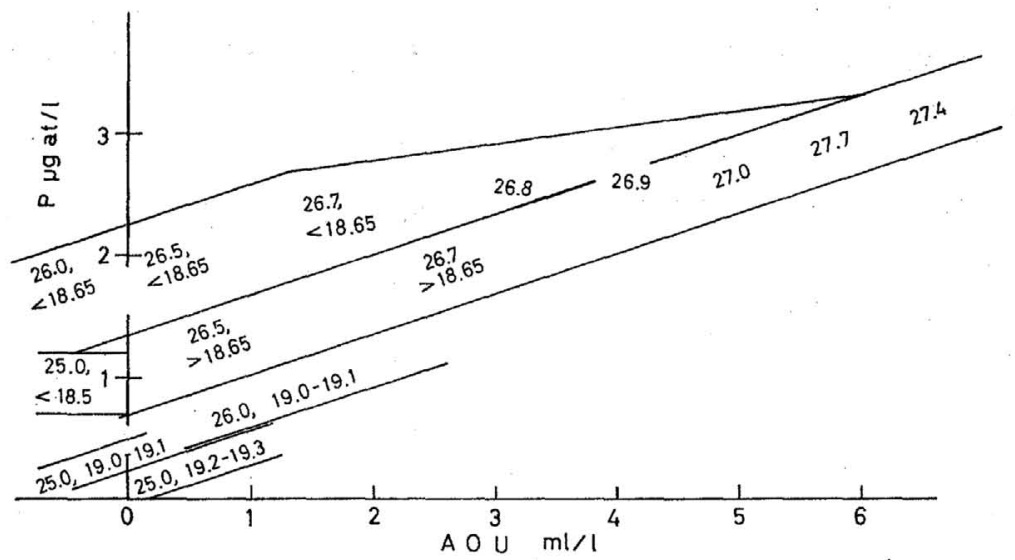

Fig. 2. The phosphate $v$ s. AOU diagram for waters of the Oyashio and the frontal region of the Kuroshio. Where double figures are shown, the upper or the former shows the $\sigma_{t}$-value and the lower or the latter shows the chlorinity-value.

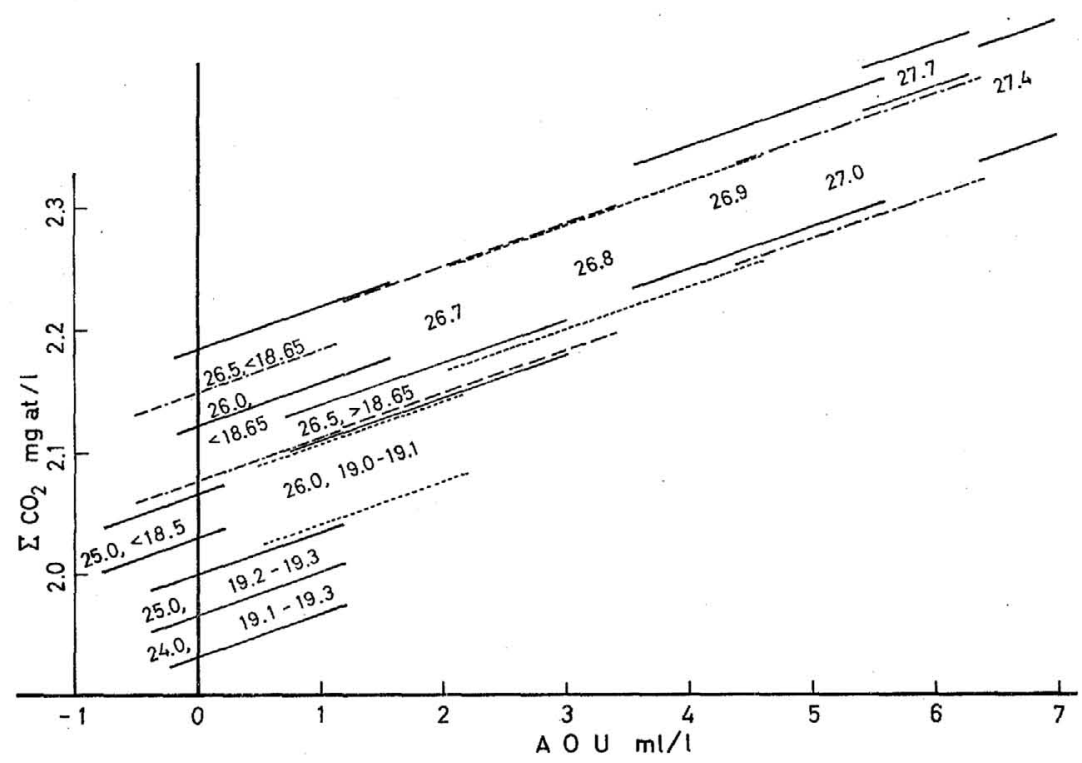

Fig. 3. The total carbon dioxide vs. AOU diagram.

surface waters). They are higher at the isopycnal planes of $\sigma_{t} 26.0$ and 26.5 in waters with chlorinity under $18.65 \%$ (the Oyashio waters) than in waters with chlorinity over $18.65 \%$ (the Kuroshio waters). However, discrepancies are found between distributions of phosphate and total carbon dioxide at the following points: The concentration of reserved phosphate is higher at the isopycnal planes of $\sigma_{t} 26.0$, 26.5 and 26.7 in waters with chlorinity under $18.65 \%$ (the Oyashio waters) than at 
the isopycnal planes of $\sigma_{t} 26.5$ and 26.7 in waters with chlorinity over $18.65 \%$ (the Kuroshio waters) and also higher than at the isopycnal planes of $\sigma_{t} 27.0,27.4$ and 27.7 in deep waters. But it is difficult to find out such a trend in the distribution of reserved total carbon dioxide among these groups of waters (see Fig. 3).

The relationship between $A O U$ and chlorosity-independent portion of reserved total carbon dioxide

It is noteworthy that the lowest concentration of phosphate is nearly zero, while that of total carbon dioxide is approximately $1.9 \mathrm{mg}$-at/l. Total carbon dioxide is one of the major constituents of sea water. According to the concept of constant proportionality among major constituents of sea water, the concentration of reserved total carbon dioxide composing the major part of total carbon dioxide might be proportional to chlorosity. But, if there is any regularity in the distribution of the amount of total carbon dioxide divided by chlorosity or the excess amount of total carbon dioxide subtracting the amount proportional to chlorosity from the observed one, the concept of constant proportionality can not be applied to total carbon dioxide. In fact, such a regularity is observed as shown in Figs. 4 and 5. Here, the following points are to be noticed: It is seen from Fig. 3 that the difference in the concentration of reserved total carbon dioxide is not found among waters with chlorinity less than $18.65 \%$ and $\sigma_{t} 26.0,26.5$ and 26.7 , waters with chlorinity higher than $18.65 \%$ and $\sigma_{t} 26.5$ and 26.7 , and waters with $\sigma_{t} 27.0,27.4$ and 27.7. However, as seen in Figs. 4 and 5, the excess amount of reserved total carbon dioxide and the ratio of reserved total carbon dioxide to chlorosity are larger in waters with $\sigma_{t} 26.0,26.5$ and 26.7 and chlorinity under $18.65 \%$ than in waters with $\sigma_{t} 26.5$ and 26.7 and chlorinity over $18.65 \%$ and are equal to or larger than those in waters with ot 27.0, 27.4 and 27.7.

The cause of these facts is considered to be the existence of a larger amount of reserved total carbon dioxide proportional to chlorosity, by which the difference inherent to reserved total carbon dioxide independent of chlorosity is masked (Fig.

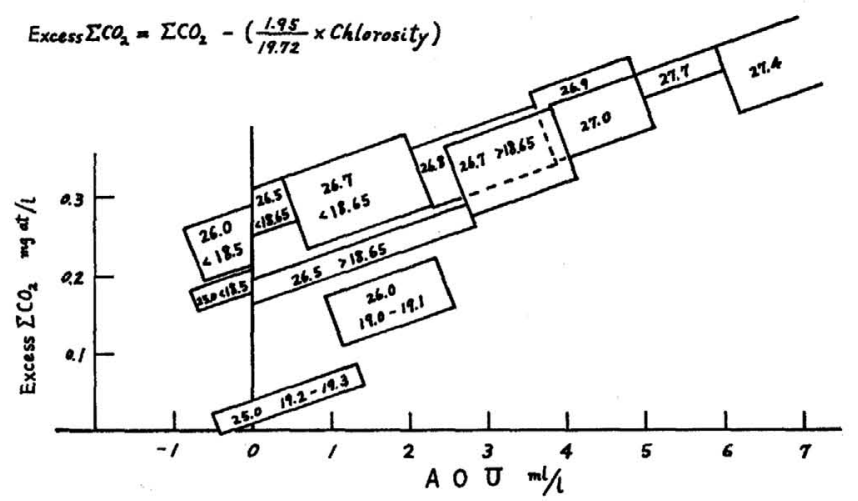

Fig. 4. The relationship between excess total carbon dioxide and AOU. 


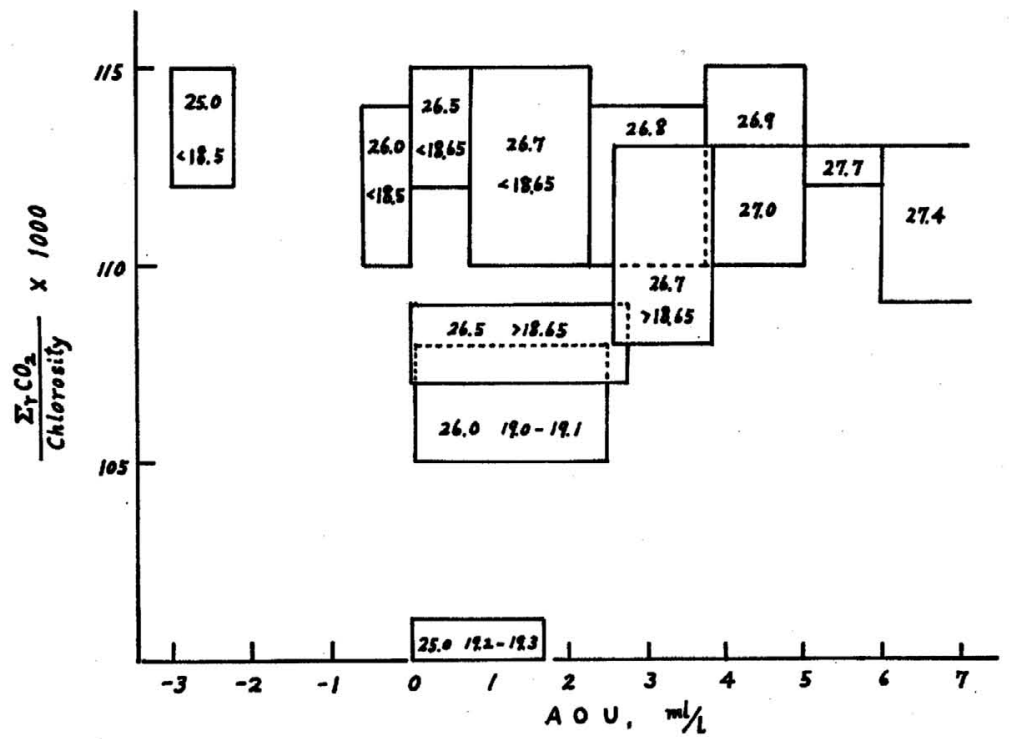

Fig. 5. The ratio of reserved total carbon dioxide to chlorosity arranged in accordance with AOU values.

3). Since the chlorosity-dependent component has been removed in Figs. 4 and 5, the difference inherent to the chlorosity-independent component is easily recognized.

In conclusion, it may be said that total carbon dioxide consists of three components; oxidative total carbon dioxide, reserved total carbon dioxide proportional to chlorosity (major portion of the reserved one) and reserved total carbon dioxide independent of chlorosity (minor portion of the reserved one).

Some explanation must be made on the difference between results in Figs. 4 and 5 concerning the location of a group of points representing waters with $\sigma_{t} 25.0$ and chlorinity less than $18.5 \%$. According to the previous study on the P-AOU relationship (SUGIURA, 1964), the uppermost surface waters with $\sigma_{t} 25.0$ and chlorinity less than $18.5 \%$ in the Oyashio region are supersaturated with oxygen and a part of oxygen escapes from the water through the surface. Waters with chlorinity less than $18.65 \%$ and $\sigma_{t} 26.7$ and 26.5 , and waters with chlorinity less than $18.5 \%$ and $\sigma_{t}$ 26.0 and 25.0 are all Oyashio surface waters above the depth of approximately 100 m. Among them, waters with ot 26.0, 26.5 and 26.7 have equal concentrations of reserved phosphate, but waters with $\sigma_{t} 25.0$ seemingly do not, as seen in Fig. 2. As they are the same Oyashio surface water, they should have the same concentration of reserved phosphate, as shown in the Kuroshio surface waters. So, the points representing waters with ot 25.0 and chlorinity less than $18.5 \%$ must fall somewhere on an extension of a straight line drawn through points representing the Oyashio surface waters with $\sigma_{t}$ 26.0, 26.5 and 26.7 (see Fig. 2).

If oxygen escapes from the sea into the air due to supersaturation, the points 
representing the Oyashio surface waters with $\sigma_{t} 25.0$ will shift towards the right parallel to the $x$-axis. As a result, the uppermost surface water seemingly has a lower concentration of reserved phosphate. The extent of the shift gives the amount of lost oxygen. The amount of reserved total carbon dioxide in Fig. 5 has been estimated by compensating for the amount of lost oxygen determined in the abovementioned way based on the $\mathrm{P}$ to AOU relationship. So, the amount of reserved total carbon dioxide shown in Fig. 5 is larger than that shown in Fig. 4 in which the lost oxygen is not taken into account. Here, it is noteworthy that the amount of reserved total carbon dioxide in the Oyashio uppermost surface waters with $\sigma_{t}$ 25.0 determined in the above-mentioned way approximately coincides with that in the Oyashio surface waters with $\sigma_{t} 26.0,26.5$ and 26.7, as shown in Fig. 5. This fact may suggest that the exchange of carbon dioxide through the air-sea interface is not so much significant as that of oxygen. This point will be discussed further in detail elsewhere.

\section{ACKNOWLEDGEMENTS}

The authors wish to express their hearty thanks to Prof. Y. Mryake, Tokyo Kyoiku University for his kind encouragement and discussion on this work. Thanks are also due to Prof. Y. Kitano, Nagoya University, for his kind discussion.

\section{REFERENCES}

FLEMING R. H. (1940) The composition of plankton and units for reporting population and production. Proc. 6th Pacific Sci. Cong. Calif. 3, 533-540.

SUGIURA, Y. and H. YOSHIMURA (1964) Distribution and mutual relation of dissolved oxygen and phosphate in the Oyashio and the northern part of Kuroshio regions. J. Oceanogr. Soc. Japan 20, 14-23.

SugiurA, Y. (1966) The total carbon dioxide in the ocean. Pap. Met. Geophys. 16, 230-236. 